\title{
Destruction of halogen-containing pesticides by means of detonation combustion
}

\author{
Jolanta Biegańska
}

Received: 9 July 2012 / Accepted: 22 October 2012 /Published online: 6 November 2012

(C) The Author(s) 2012. This article is published with open access at Springerlink.com

\begin{abstract}
Pesticides that contain a halogen functional group have been destructed by means of detonative combustion. The following compounds were examined: (1) atrazine-2chloro-4-ethylamino-6-isopropylamino-1,3,5-triazine-herbicide; (2) bromophos-O,4-bromo-2,5-dichlorophenyl $O, O$-dimethyl phosphorothioate-insecticide; (3) chloridazon-5-amino-4-chloro-2-phenylopyridazin-3(2H)-oneherbicide; (4) linuron-3-(3,4-dichlorophenyl)-1-metoxy-1methylurea-herbicide; (5) metoxychlor-1,1,1-trichloro2,2-bis(4-metoxyphenyl)ethane-insecticide and acaricide; and (6) trichlorfon-dimethyl 2,2,2-trichloro-1-hydroxyethylphosphonate-insecticide. Explosive material has been produced on the basis of ammonium nitrate, which served as an oxidizer while the pesticides were used as fuels. Composition of the explosive was adjusted in such a way as to respect thermodynamic parameters. Detonative decomposition of the mixtures has been carried out in shot-holes predrilled in soil. Efficiency of the pesticide decomposition has been examined with gas chromatography in order to determine pesticides residues in the environment. It was found that for some, the amount of pesticides in some compounds in the analyzed samples after decomposition was below the determination threshold of the applied method.
\end{abstract}

Keywords Pesticides - Detonative decomposition · Waste disposal

Responsible editor: Philippe Garrigues

J. Biegańska $(\bowtie)$

Faculty of Energy and Environmental Engineering, Department of

Technology and Installations for Waste Management, Silesian

University of Technology,

18, Konarskiego St,

44-100 Gliwice, Poland

e-mail: olaiii@wp.pl

\section{Introduction}

Organochlorine pesticides are dispersed in the environment - they even appear in locations that are far away from agricultural and industrial areas. Number of organochlorine compounds that have been identified in the environment (Skrbic and Durisic-Mladenovic 2007; Hosie 2000; Pavoni et al. 2006; Grynkiewicz et al. 2003) amounts to about $15,000,50 \%$ of which are difficult to decompose. Organochlorine compounds are accumulated in animal fat tissue.

Biodegradation of organochlorine is a complex process and active chemical reactions may lead to formation of metabolites that are even more toxic than the original reactants. Furthermore, pesticide wastes that have been stored in burial grounds (Wołkowicz et al. 2005; Gałuszka et al. 2011) pose the most critical threat to the environment. Organochlorine compounds (Gałuszka et al. 2011) constitute about $30 \%$ of all the pesticides that are stored in the burial grounds in Poland.

The literature sources describe various methods of the waste pesticides disposal (Salvestrini et al. 2002; Seiber 1992; Mahamuni and Adewuyi 2010; Legrini et al. 1993; Kim et al. 2011). Biological, physical, chemical, and thermal methods are depicted. Problem of pesticide wastes is the never-ending subject of research, as new methods and ways of neutralization and detoxication of hazardous deposits are still searched for. The present paper describes decomposition of several halogen-containing pesticides by means of detonative combustion.

\section{Experimental part}

It was assumed that ammonium-nitrate fuel oil (ANFO) would be used as a heterogeneous explosive material, where 


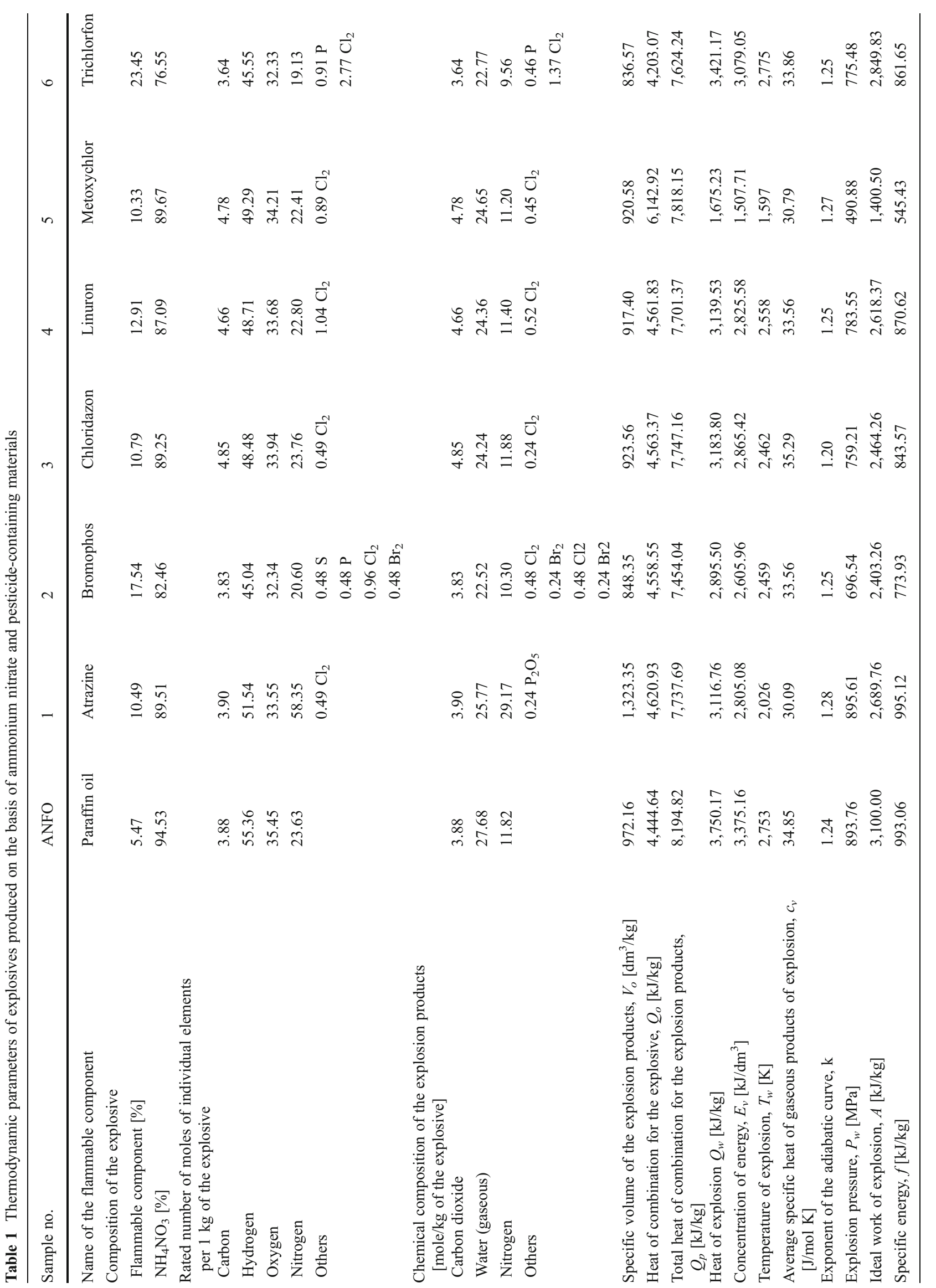


porous ammonium nitrate would act as oxidizer and the pesticide would be used as fuel. Containers were filled with explosive mix composed of $a \%$ of $\mathrm{NH}_{4} \mathrm{NO}_{3}$ and $b \%$ flammable component (pesticide-fuel).

Composition of mixtures that contain some porous ammonium nitrate and the examined pesticide have been designed in such a way that the obtained explosive reach density of $d=0.900 \mathrm{~kg} / \mathrm{dm}^{3}$ and oxygen balance $B=0 \%$. For the designed explosive mixtures, the thermodynamic parameters have been calculated in order to determine temperature of the explosions, considering that the temperature should be high enough to assure decomposition of the pesticide.

The obtained results are presented in Table 1. For comparison, the table shows parameters of the typical explosive ANFO produced from ammonium nitrate and paraffin oil.

\section{Detonative decomposition in soil}

Plastic PET container of $180-\mathrm{mm}$ diameter and $5-\mathrm{dm}^{3}$ capacity was used to decompose pesticides by means of detonative combustion. The explosive material was introduced to the container. A 2-kg load of explosive (ANFO) and pesticide was prepapred. Then the load was furnished with the NONEL detonator and placed into a previously prepared shot hole in the soil at the depth of $120 \mathrm{~cm}$, protected by stemming.

Next, a blasting cap tied to a blasting fuse was attached to NONEL cord. Such a load, placed in the hole, was fired. The procedure-calculations, blast-hole dimensioning, soil sampling - was similar to the procedure described in Biegańska (2005) for the decomposition of DNOC in soil.

After detonation of the explosive, soil samples were taken for analysis. For sampling, five boreholes were made with a manual drill (gimlet). Each borehole had a diameter of $10 \mathrm{~cm}$ and the depth of $140 \mathrm{~cm}$ (with reference to the level before detonation).

The soil, sampled from each borehole, was placed on plastic foil and thoroughly mixed. Such samples were taken for analysis.

Preparation of samples for determination of pesticide content

Weighted samples of soil $(50 \mathrm{~g})$ were drenched with two portions of chloromethane of $50 \mathrm{~cm}^{3}$ each, one after another. Afterwards, the extraction in an ultrasonic bath was carried out (Ashley 1995). The extracts were filtered and dried in a

Fig. 1 Chromatogram of atrazine

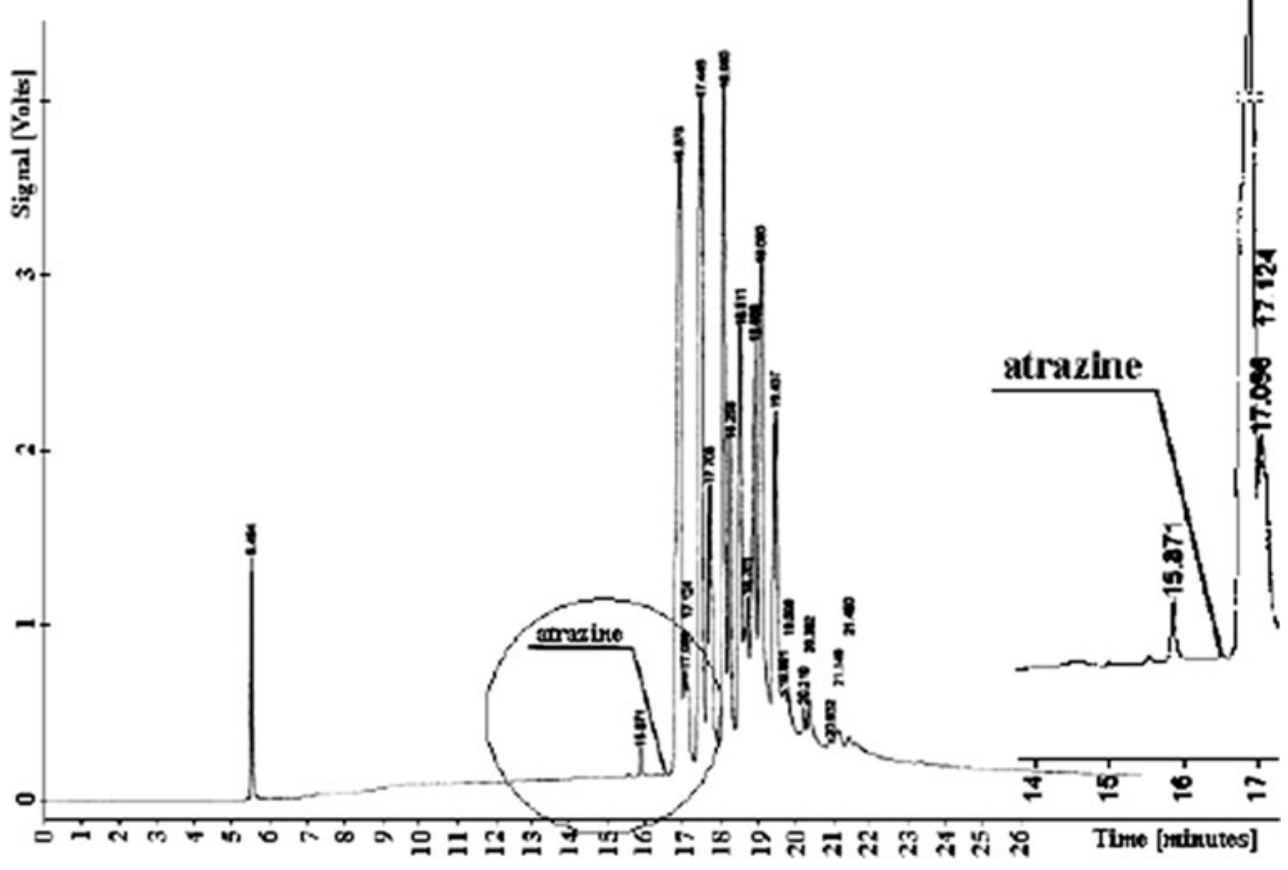


Fig. 2 Chromatogram of bromophos

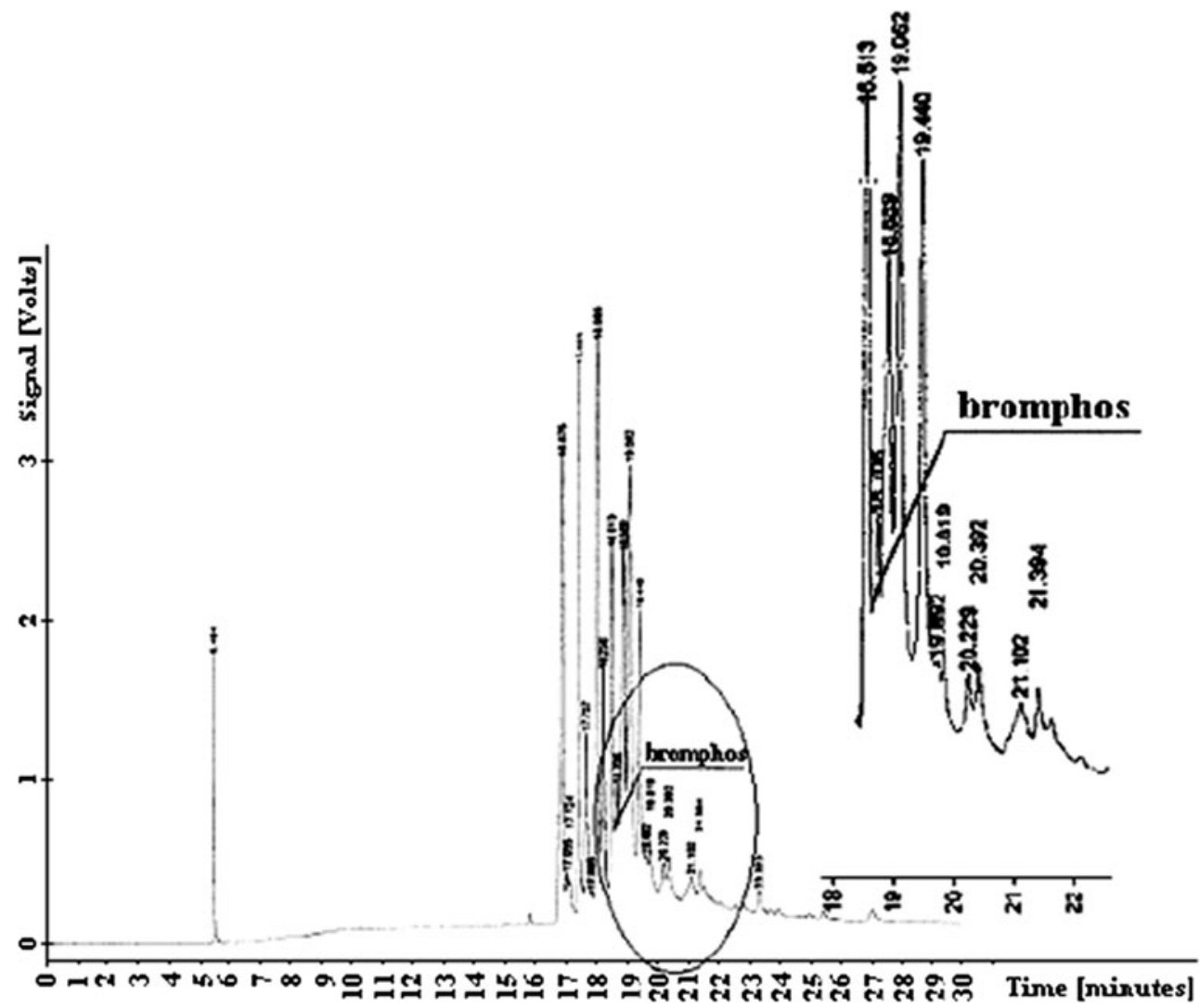

vacuum evaporator. The dry residues were standardized by dissolving in $10 \mathrm{~cm}^{3}$ of acetone. After such preparation, the sample was analyzed for the content of biologically active substances.

Fig. 3 Chromatogram of chloridazon

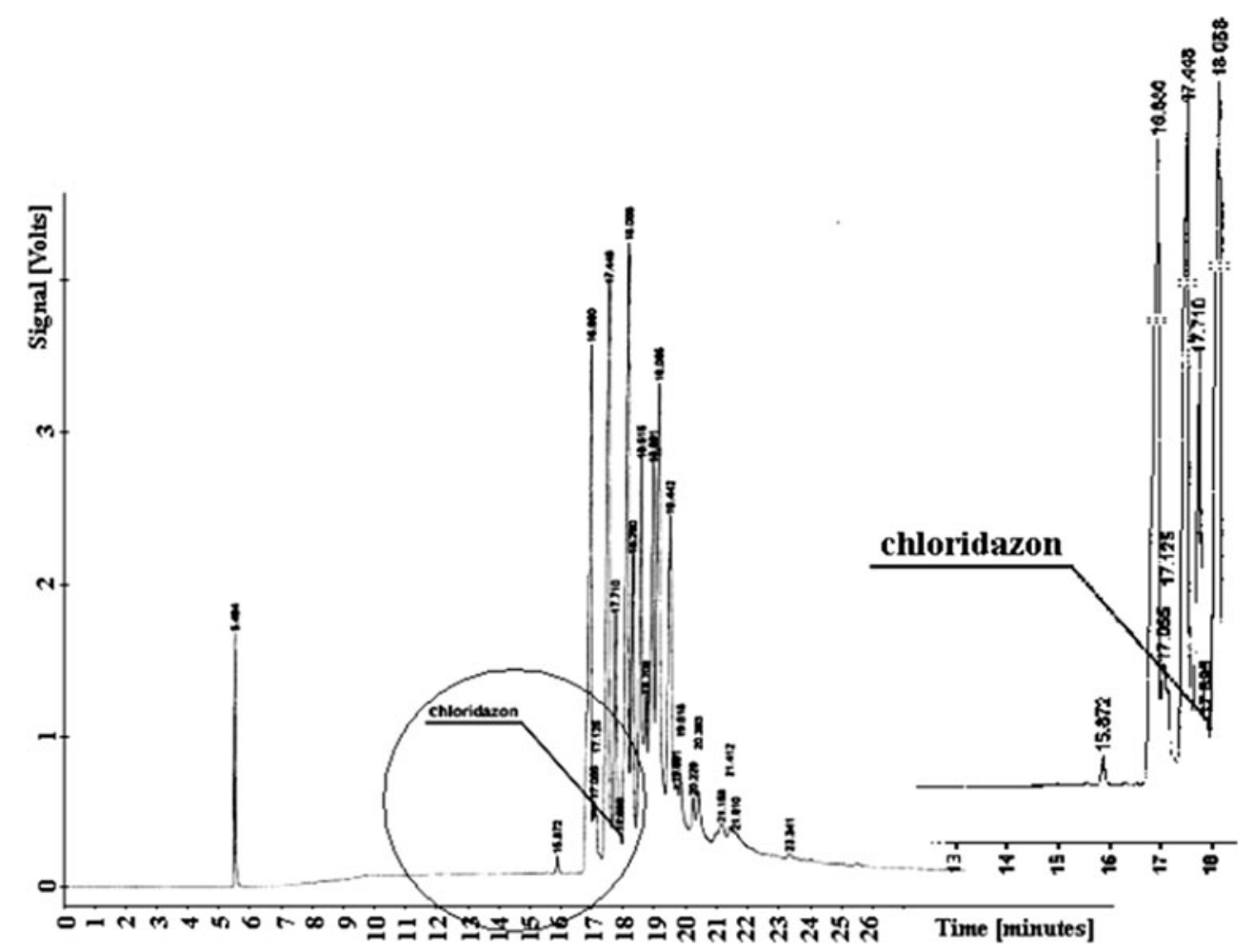


Fig. 4 Chromatogram of linuron

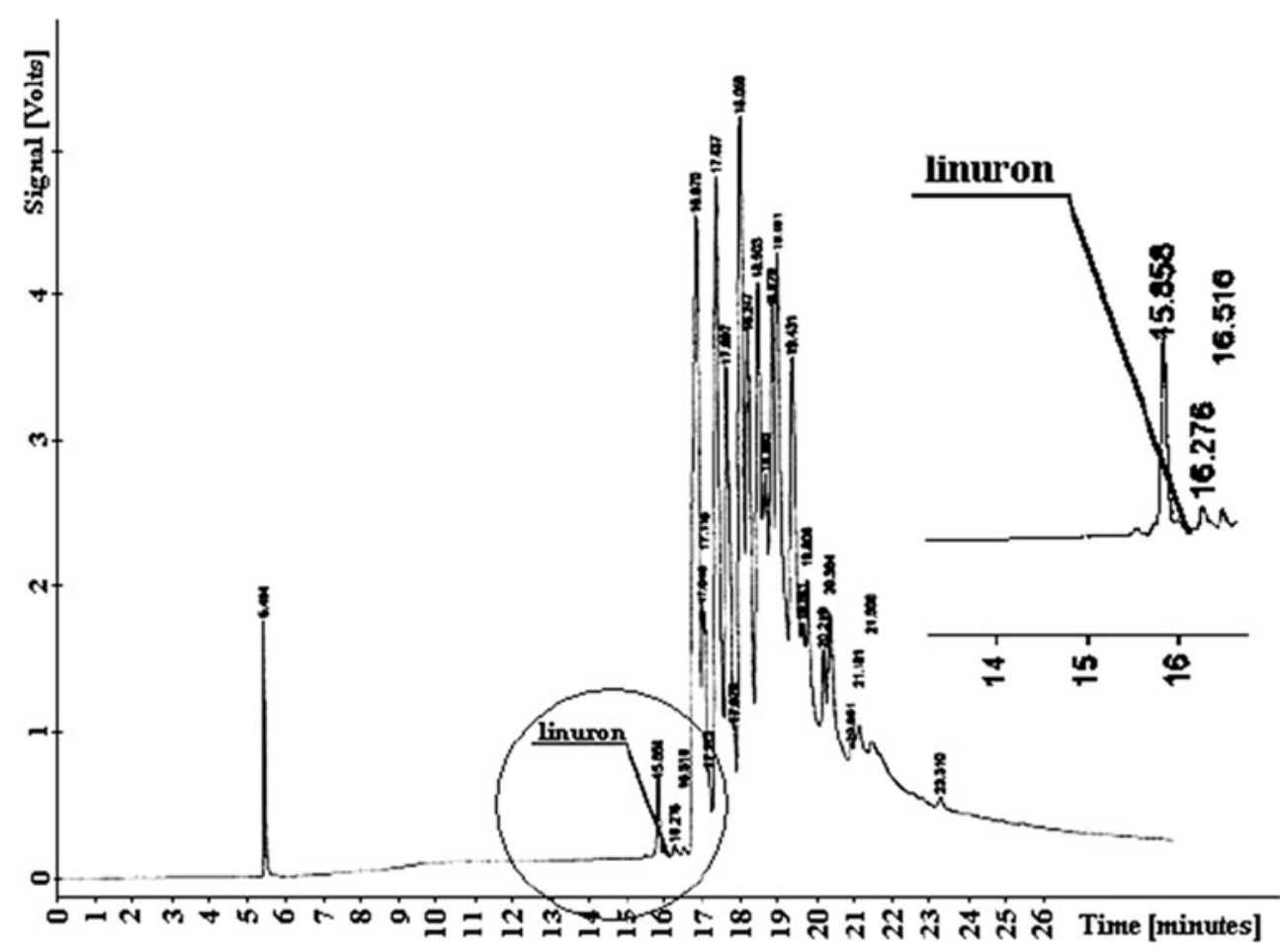

Estimation of pesticide content in soil by means of gas chromatography method

The amount of pesticides remaining in extracts prepared from the soil samples was determined using gas chromatography method. A gas chromatography analysis has been performed by Varian type 3400, equipped with the electron capture detector and an integrator, marked with the IBDH symbol for automatic data processing. Chromatographic separation of components was carried out in a capillary column made of silica (silicon dioxide) with chemical connection to the liquid phase. The capillary column was factory labeled as DB-5. Internal diameter of the column was $0.25 \mathrm{~mm}$ and thickness of the phase film was $0.25 \mu \mathrm{m}$. The column was $30 \mathrm{~m}$ long. Thermal conditions of the separation were as follows: temperature of the feeder was $553 \mathrm{~K}$ and temperature of the detector was $573 \mathrm{~K}$. Over the first 5 min temperature of the column was set at $353 \mathrm{~K}$, then programmed to gradual heating at the rate of $10 \mathrm{grads} / \mathrm{min}$, up to $563 \mathrm{~K}$. Helium, at its flow rate of $1 \mathrm{ml} / \mathrm{min}$, served as the carrier gas. The component to be determined was identified by comparing retention time of given substance.

The extracts prepared from the soil contain remaining amounts of pesticides, if any, but also other organic compounds,
Fig. 5 Chromatogram of metoxychlor

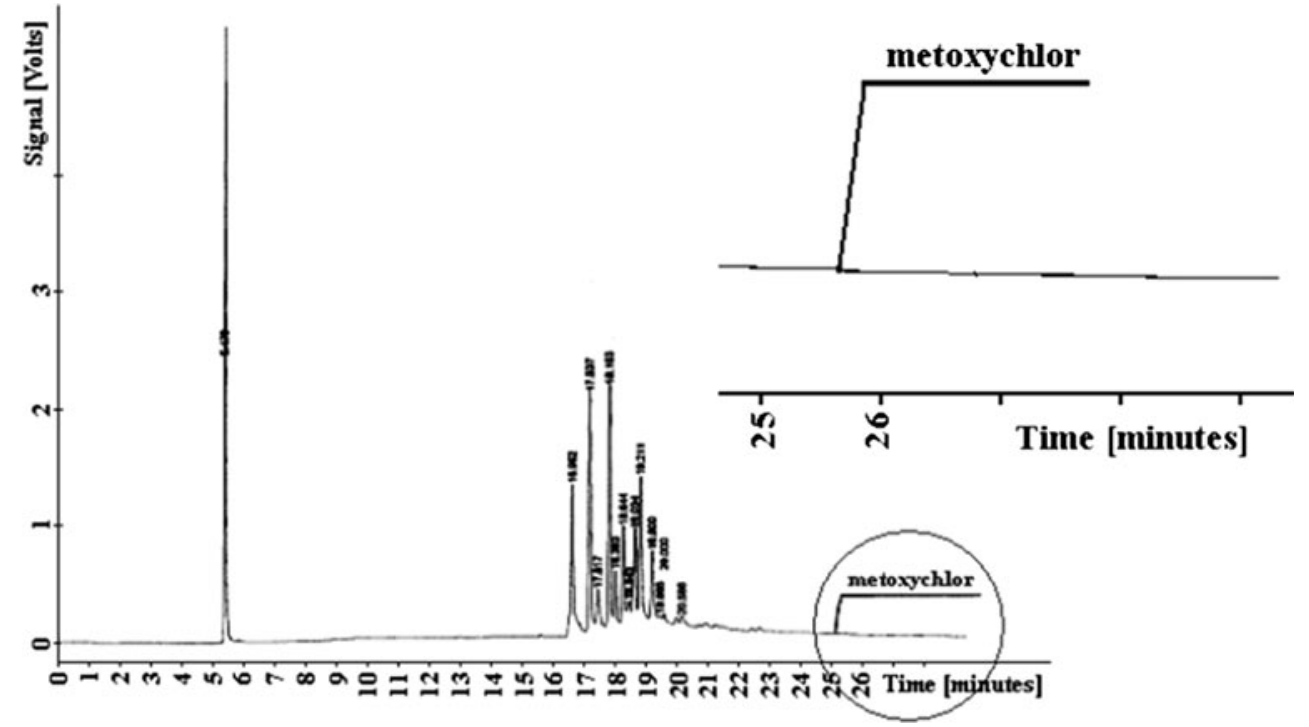


Fig. 6 Chromatogram of trichlorfon

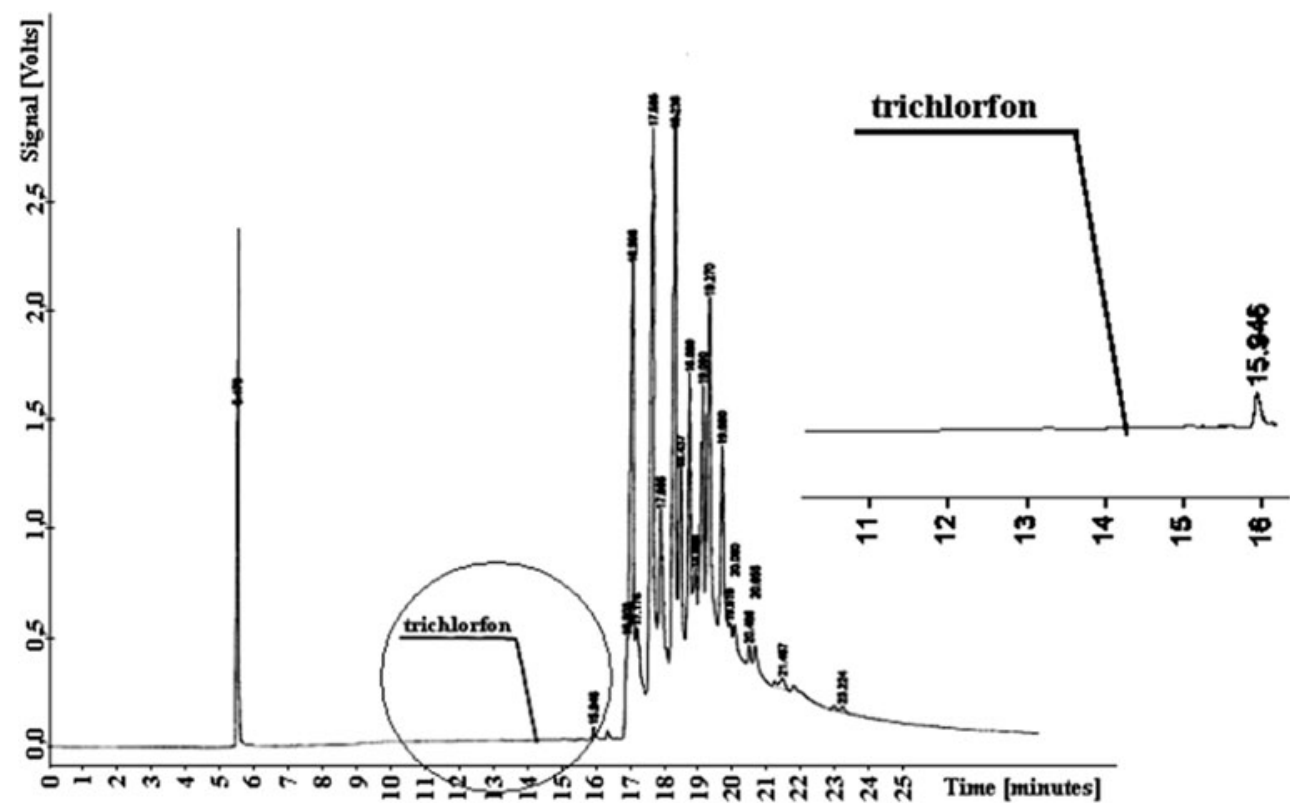

which become volatile under thermal conditions of gas chromatography. That is why the chromatograms present peak areas that correspond respectively to organic components of soil and the investigated pesticides. Approximately half of the compounds to be determined elute outside the elution range for the soil components. The other half elutes during the same or similar retention time.

In the first case, the detector emits signal in the form of a peak and numerical value which represents the amount of the determined pesticides. Lack of that signal should be the understood as the proof that no pesticide was detected.

In the second case, signal from the detector that corresponds to the compound to be determined may be located among signals which correspond to particular components of soil. Such signal when identified is used directly to mark the amount. The retention times may be so similar that they merge into a common signal. In such case, it is required to calculate values which correspond to the component to be determined from the overlaping part.

The above calculations are founded on methods used in gas chromatography to mark hidden components. They are based on the proportion of peak amplitudes or numerical signals selected separately for each case. These peaks (values) should be identified on chromatograms from a reference test sample and the analyzed one. The blind sample is an extract from soil that is used for technological experiments, whereas the analyzed sample is an extract of the same soil mixed with the pesticide and decomposed with the explosive.

Serial studies on chromatography show that the chromatogram for the analyzed sample is considered to be a "blind" chromatogram, but without the section that covers the peak of the component to be determined and with the peaks directly preceding and following the analyzed peak. As the components to be determined elute at different retention times, such an approach is reasonable and commonly used.

Signal value for the component to be determined was calculated from the common value for two or more components on the basis of the proportion rates in the following way: a peak area-point of reference was selected on the chromatogram for the reference sample. It had the retention time slightly different than the retention time of the component to be determined. The numerical value of the signal equaled $a$. Similarly, a peak or a group of peaks were selected that could include the peak area of the components
Table 2 Residual content of crop protection agents in the soil after their detonative decomposition

\section{$d t$ determination threshold for} the biologically active agent, $b d t$ below the determination threshold, $p g o=$ adt $=$ above the determination threshold

\begin{tabular}{lllll}
\hline Sample no. & Preparation (commercial name) & Active agent & Result, mg/kg & Remarks \\
\hline 1 & Gesaprim 50 WP & Atrazine & pgo & $\mathrm{dt}=7.5 \mathrm{mg} / \mathrm{kg}$ \\
2 & Nexion EC 40 & Bromophos & 3.64 & $\mathrm{dt}=1.0 \mathrm{mg} / \mathrm{kg}$ \\
3 & Pyramin 65 WP & Chloridazon & 9.28 & $\mathrm{dt}=4.0 \mathrm{mg} / \mathrm{kg}$ \\
4 & Afalon 50 WP & Linuron & $\mathrm{bdt}$ & $\mathrm{dt}=2.75 \mathrm{mg} / \mathrm{kg}$ \\
5 & Liquid Metox 30 & Methoxychlor & $\mathrm{bdt}$ & $\mathrm{dt}=5.0 \mathrm{mg} / \mathrm{kg}$ \\
6 & Liquid Foschlor 25 & Trichlorfon & $\mathrm{bdt}$ & $\mathrm{dt}=0.5 \mathrm{mg} / \mathrm{kg}$ \\
\hline
\end{tabular}


to be determined with the numerical value of signals equal to $b$. The ratio $a / b$ has a specific value. The same peaks on the chromatogram of the analyzed sample reach the respective numerical values of $c$ and $d$. The ratio $a / b=c / x$ gives the value of $x$ if the tested sample does not contain any amounts of the component to be determined. The difference $d-x=g$ is value of the hidden signal of the component to be determined.

Following the procedure, certain sample amount of solution was introduced into the device in order to create chromatogram. Then, the chromatogram was drawn and processed according to the description. The numerical values of the signals either read from the detector or calculated for the components to be determined were introduced as input data for the integrator that stored in its memory relevant parameters of calibration curves. Finally, results of determination of the components were given through mathematical computations.

\section{Results and discussion}

The atrazine elutes from the column at $t_{R}=16.576$, earlier than the soil component. Therefore, the analytic procedure is simple-Fig. 1 shows chromatograms from the determination of atrazine in samples of neutral and acid extraction. The chromatograms printouts showed neither peak areas nor detector signals that would reflect pesticide residues.

Bromophos elutes from the column at $t_{R}=18.678$ together with the group of soil components. Hidden signal was calculated from the ratio of the reference peak at $t_{R}=18.065$ and the sum of peak values at $t_{R}=18.513, t_{R}=18.706$ and $t_{R}=18.889$, considering chromatograms for the blind sample and analyzed samples. Figure 2 presents chromatogram of determination of that compound.

Chloridazon elutes from the column at $t_{R}=17.895$ together with the group of soil components (Fig. 3). Linuron elutes from the column earlier than the coil components at $t_{R}=$ 16.072. The early elution is a factor that facilitates analysis of the samples. The chromatograms for determining content of that compound are shown in Fig. 4. The diagrams present no peaks that would refer to linuron and no respective detector signal printouts could be obtained.

Metoxychlor elutes with the retention time $t_{R}=25.572$ after the soil components. The related chromatogram for the component remainder with the retention parameter marked on the diagram is shown in Fig. 5.

The trichlorfon elutes from the column at $t_{R}=14.244$, earlier than the soil components. Hence, determination of that component presents no difficulty. Figure 6 shows a typical chromatogram with the retention parameter of the compound marked.

Results of determining the residual content of crop protection agents in soil have been summarized in Table 2. The chromatography showed that residues of only two biologically active components of pesticides, namely bromophos and chloridazon were present in soil after detonative combustion.

For the majority of the pesticides, detonative decomposition left insignificant amounts of biologically active compounds. Amounts of chemicals in samples identified after the detonations were below the determination threshold. This proves that the hazardous substances have been decomposed to a very high degree.

The achieved results allow to draw a conclusion that the waste pesticides that contain halogens can be used to manufacture explosives of ANFO type widely used in open-cut mining industry for getting limestone.

Open Access This article is distributed under the terms of the Creative Commons Attribution License which permits any use, distribution, and reproduction in any medium, provided the original author(s) and the source are credited.

\section{References}

Ashley K (1995) Ultrasonic extraction and field portable anodic stripping voltammetry of lead from environmental samples. Electroanalysis 7:1189-1192

Biegańska J (2005) Neutralization of 4,6-dinitro-o-cresol waste pesticide by means of detonative combustion. Environ Sci Technol 39:1190-1196

Gałuszka A, Migaszewski ZM, Manecki P (2011) Pesticide burial grounds in Poland: a review. Environ Int 37:1265-1272

Grynkiewicz M, Polkowska Ż, Górecki T, Namieśnik J (2003) Pesticides in precipitation from an urban region in Poland (GdańskSopot-Gdynia) between 1998 and 2000. Water Air Soil Pollut 149:3-16

Hosie S, Loff S, Witt K, Niessen K, Waag KL (2000) Is there a correlation between organochlorine compounds and undescended testes? Eur J Pediatr Surg 10:304-309

Kim K, Tsay OG, Atwood DA, Churchill DG (2011) Destruction and detection of chemical warfare agents. Chem Rev 111:5345-5403

Legrini O, Oliveros E, Braun MM (1993) Photochemical processes for water treatment. Chem Rev 93:671-698

Mahamuni NN, Adewuyi YG (2010) Advanced oxidation processes (AOPs) involving ultrasound for waste water treatment: a review with emphasis on cost estimation. Ultrasonics Sonochemistry 17:990-1003

Pavoni B, Drusian D, Giacommeti A, Zanette M (2006) Assessment of organic chlorinated compound removal from aqueous matrices by adsorption on activated carbon. Water Res 40:3571-3579

Salvestrini S, Cerbo PD, Capasso S (2002) Kinetics of the chemical degradation of diuron. Chemosphere 48:69-73

Seiber JN (1992) Current technologies for pesticide waste disposal. ACS Symp Ser 510:138-147

Skrbic B, Durisic-Mladenovic N (2007) Principal component analysis for soil contamination with organochlorine compounds. Chemosphere 68:2144-2152

Wołkowicz S, Choromański D, Wołkowicz W, Strzelecki R (2005) Liquidation and recultivation of repositories containing unwanted pesticides in Poland: current status and perspectives for solving the problem. Pol Geol Inst Spec Pap 17:89-93 